\title{
Successful pregnancy after uterine artery embolization for uterine arterovenous malformation: a rare case report
}

This article was published in the following Dove Press journal: International Journal of Women's Health

\section{Guida' \\ D Maffucci' \\ G Iannuzzi' \\ M Giordano' \\ G Luciano' \\ L Di Benedetto 2 \\ R Cantarella ${ }^{3}$ \\ A Rescigno ${ }^{3}$ \\ L Giugliano'}

'Università degli studi di Salerno Dipartimento di Medicina, Chirurgia e Odontoiatria "Scuola Medica Salernitana", Salerno, Italy; "Università degli studi di Roma "La Sapienza" - Dipartimento di Scienze Medico-Chirurgiche e di Medicina Traslazionale - Facoltà di Medicina e Psicologia Azienda Ospedaliera Sant' Andrea, Rome, Italy; ${ }^{3}$ Azienda Ospedaliera Universitaria San Giovanni di Dio e Ruggi D’Aragona, Salerno, Italy
Correspondence: G lannuzzi Università degli studi di Salerno Dipartimento di Medicina, Chirurgia eOdontoiatria "Scuola Medica Salernitana", Via Arce 33, Salerno 84I25, Italy

Email gabriellaiannuzzi9@gmail.com
Objective: This paper reports on a rare case of pregnancy after uterine artery embolization (UAE) for uterine arteriovenous malformation (AVM). Debate exists about persistence of fertility in women after UAE. Adverse effects of this technique can modify both uterine echostructure, inducing necrosis and infarction, endometrial atrophy and uterine artery rupture, and ovarian reserve, causing persistent amenorrhea. Ovarian reserve appears to be affected by UAE in premenopausal women. However, younger ovaries (according to biological ovarian age) exhibit a greater capacity for recovery after ovarian damage. Therefore, larger studies are needed for more conclusive results.

Case report: A 28-year-old woman was admitted to our department due to life-threatening uterine bleeding, resulting in tachycardia, pallor, and sweating. The patient came with a history of two spontaneous miscarriages. After sonography and computed tomography, AVMs were identified at uterine fundus and anterior wall.

Conclusion: The pathogenesis of infertility after UAE is not yet known. The peculiarity of this case was that, only few months later, the patient became pregnant and gave birth to a live fetus at 37 weeks with cesarean delivery.

Keywords: uterine artery embolization, fertility, uterine arteriovenous malformation, pregnancy, angiography

\section{Introduction}

Arteriovenous malformations (AVMs) are rare but potentially lethal lesions, responsible for pelvic hemorrhage eventually.

Apart from rare congenital cases, almost every case arises after trophoblastic disease, previous curettage, pelvic surgery, endometrial or cervical malignancy, diethylstilbestrol exposure, and uterine infection. ${ }^{2}$

AVMs are abnormally connected vessels, often arteries and veins interconnected by fistulae. Sometimes, capillaries intertwine with this vascular network.

Although some cases have been found in adolescent and postmenopausal women, fertile age represents the most frequent period for AVMs discovery. Pregnancy, miscarriage, induced abortion, and trophoblastic disease are critical events for pathogenesis of these malformations. After chorionic villi necrosis, the incorporation of venous sinuses in scars within the myometrium leads to the development of AVMs. Generally, trophoblast invades uteroplacental arteries during the first two trimesters, inducing artery enlargement resistance reduction. Then, during the third trimester, re-endothelialization takes place. Some authors suggest that involution of placental bed vessels could cause uterine AVMs. 
According to this theory, in subinvolution of placental bed vessels, uteroplacental arteries maintain characteristics similar to those of the first two trimesters. ${ }^{3-5}$

Rare congenital cases have been found in Rendu-OslerWeber disease, Cowden syndrome, or Bannayan-RileyRuvalcaba syndrome.

The most common clinical presentation is pelvic bleeding, which can cause hemorrhagic shock and anemia. Anemic and hemodynamically unstable patients need treatment; women with only a single episode of metrorrhagia and hemodynamically stable should only be monitored. In the latter, a conservative approach using methylergonovine maleate, danazol, and Gn-RH agonists is recommended. ${ }^{6}$

A three-dimensional computed tomography (CT) (16-32 T) represents the gold standard for diagnosis, however, transvaginal color Doppler ultrasound is equally efficient and no invasive. AVMs appear as areas of abnormal turbulent vascularity within myometrium, with irregular morphology. Angiography is now used only for therapeutic treatments.

Traditionally, pelvic AVMs were surgically treated, with hysterectomy or uterine artery ligation, negating the opportunity for future pregnancies.

An alternative approach is represented by endovascular treatment, through femoral artery. Actually, endovascular technique includes different embolic agents: particles, plug, glue, absorbable gelatin sponge, and Onyx.

\section{Case report}

A 28 -year-old woman, gravida 2, para 0 , was admitted to our department due to severe uterine bleeding (pictorial blood loss assessment chart score $>100$ ), resulting in tachycardia, pallor, and sweating. She referred an interesting clinical history.

At the age of 26 years, a $80.4 \times 73.5 \mathrm{~mm}$ myomic nodule was diagnosed on the right side of the uterine wall by routine gynecological sonography. Following failure of therapy with enantone (11.25 fl), it was proposed for laparoscopic myomectomy surgery performed on 31/01/2014.

At the age of 27 years, the patient had a spontaneous miscarriage at eighth week of gestation, for which a uterine curettage was performed.

Six months later, the patient was admitted for another uterine curettage owing to spontaneous miscarriage at 7 weeks and 4 days of gestation.

Sonography revealed the presence of two gestational sacs, one on the left with embryonic nonpulsating echoes and one on the right with no embryonic echoes but only the yolk sac.
In the latter, the chorion appeared thickened and irregular with thin residual myometrium. Doppler showed a rich vascularization of the chorionic tissue. The presence of placental thickening, a very high $\beta$-hCG value $(214,199 \mathrm{mUI} / \mathrm{mL})$ and a cystic right ovary, suggested the occurrence of gestational trophoblastic disease.

At the age of 28 years, sonography and CT scan showed an uterus with slightly increased volume with innumerable, coarse, and serpiginous vascular ectasia in the peripheral muscle tissue (Figures 1 and 2).

These ectasias were fed by arterial branches from hypogastric circle at both sides and right ovarian artery.

The abnormal circulation showed wide sacciform dilatation in the vascular wall reaching $23 \mathrm{~mm}$ diameter. Refluent circulation was directed toward the hypogastric veins and the external iliac arteries.

The patient showed surprise because she had never heard of this disorder and dismay for fear of not being able to cure it. She was not on bed rest, and she had not taken extra medicines.

Three months later, the patient came to the Emergency Room of Obstetric and Gynecology Department of A.O.U San Giovanni di Dio e Ruggi D'Aragona, with massive uterine bleeding. Her hemoglobin level was $5.4 \mathrm{~g} / \mathrm{dL}$, red blood cells (RBC) $2.15 \times 10^{6} / \mu \mathrm{L}$, and hematocrit $19.3 \%$.

She was transfused with four blood bags of concentrated red cells.

The patient was carried to interventional radiology where she signed an informed consent and was treated

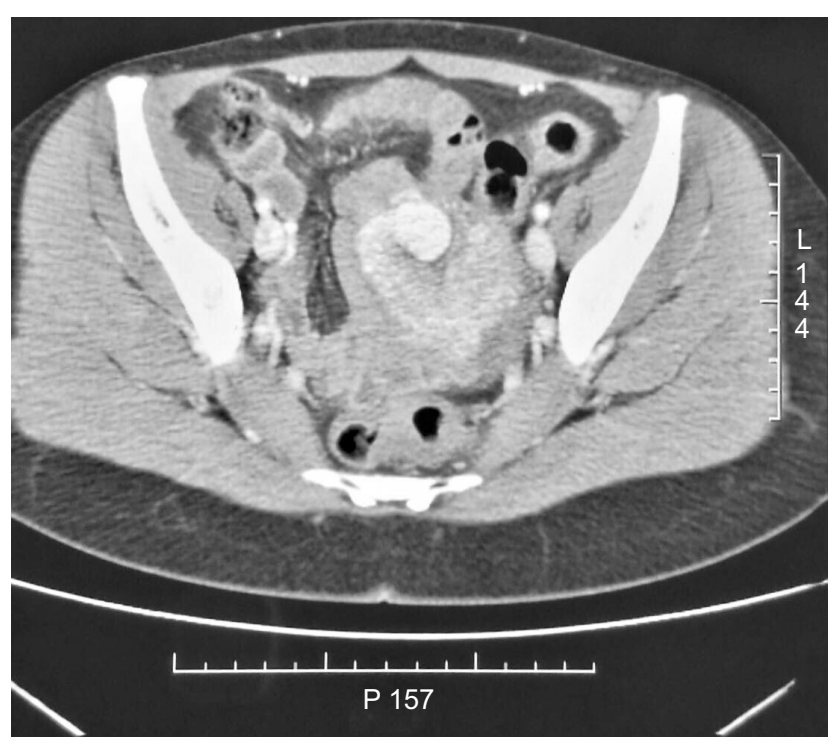

Figure I Axial CT image of presumed diagnosis of a uterine AVM in a 28-year-old patient.

Abbreviations: AVM, arteriovenous malformation; CT, computed tomography. 


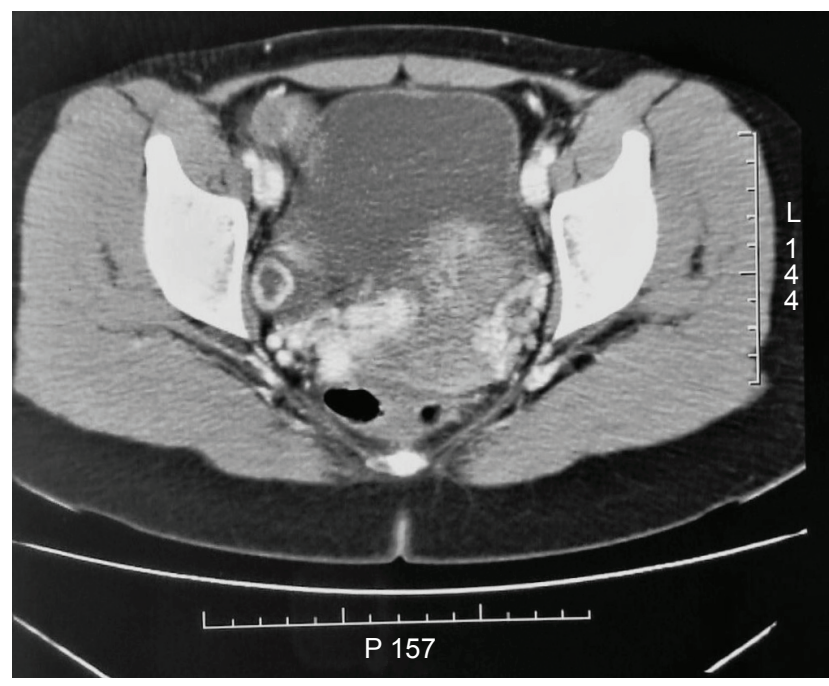

Figure 2 CT scan shows a uterus with slightly increased volume with innumerable, coarse, and serpiginous vascular ectasia in the peripheral muscle tissue.

Abbreviation: $\mathrm{CT}$, computed tomography.

with UAE in the angiography room (in the presence of an anesthetist).

This team has treated similar cases using the same technique of embolization in the same University Hospital. The five cases of uterine arteriovenous malformation (AVM) treated with this technique did not affect the fertility of the patients. Patients were advised to wait for a period of 6 months before becoming pregnant and a CT scan was performed after embolization to ensure the disappearance of AVM. All the patients became pregnant without complications. None had abortions.

Uterine artery embolization (UAE) is a mini-invasive technique. ${ }^{7-9}$ It includes peripheral artery access (preferred femoral) and injection of embolic stuff in uterine arteries. Usually, only a femoral artery access is sufficient to reach both uterine arteries.

In our case, through percutaneous access from right femoral artery to both hypogastric arteries, uterine arteries were reached, where a bilateral superselective catheterization was performed (Terumo-SP). (Figure 3) After angiographic morphological study of the target vessels, the embolic material (Onyx: ethylene vinyl alcohol copolymer [EVOH]) was injected (Figure 4).

It is composed of a part of properly embolic material (EVOH) and a solvent, which prevents the Onyx solidification into the catheter (DMSO).

The embolization was stopped when the nidus appeared totally embolized by Onyx (Figure 5).

The patient was monitored for 5 days in our department, and treated with oral iron supplement, folic acid, and meropenem.

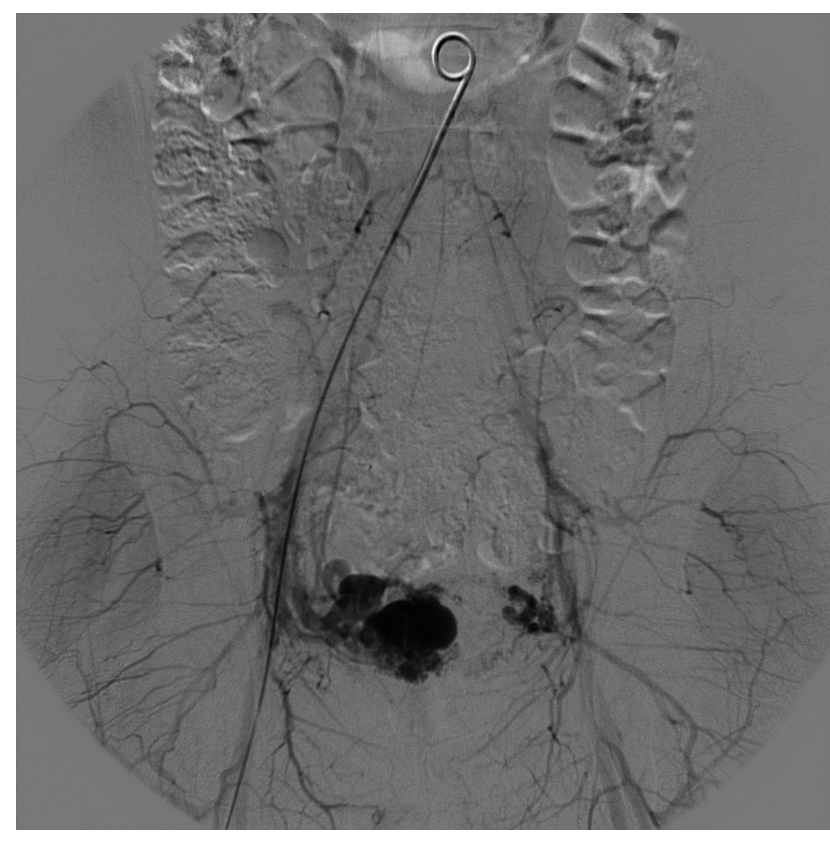

Figure 3 Pelvic angiogram shows a bilateral superselective catheterization.

She was submitted to control sonography and CT that confirmed the disappearance of vascular ectasia.

Five months after UAE, the patient became pregnant.

Sonography showed the presence of a single gestational sac in uterus, containing an embryonic pole with cardiac activity, with a $10 \mathrm{~mm}$ crown rump length (CRL), according to amenorrhea period.

Ultrasound showed a placenta with an anterior insertion with a little area of abruption $(5 \times 2 \mathrm{~mm})$ at the superior pole.

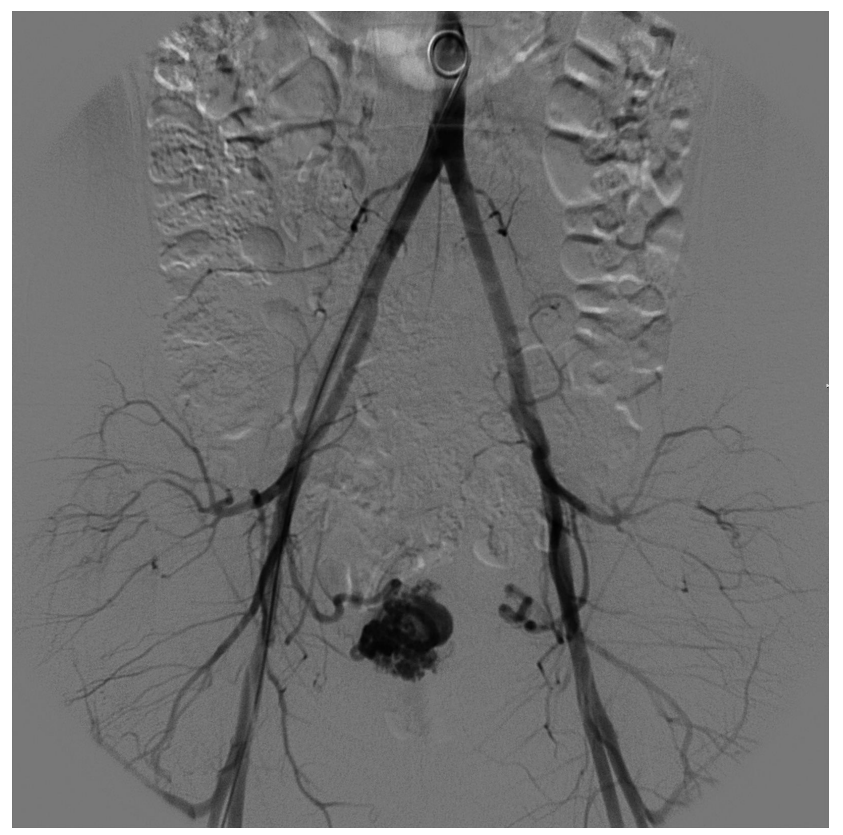

Figure 4 Pelvic angiogram shows a dilated and tortuous right uterine artery. 


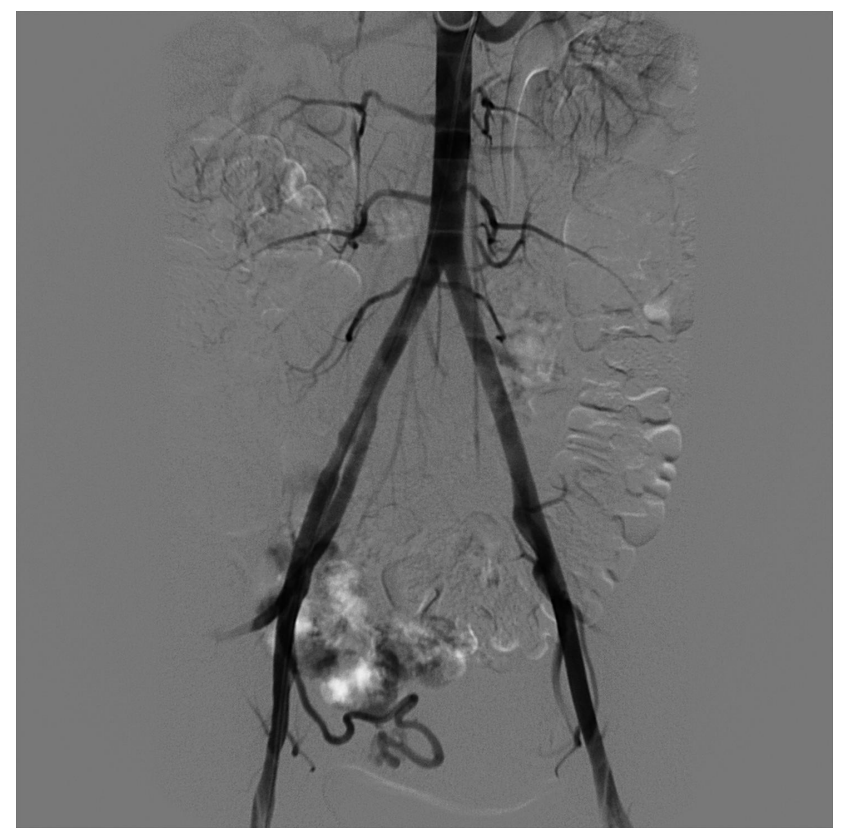

Figure 5 Pelvic angiogram shows the nidus totally embolized by Onyx.

The patient, bed resting, was treated with vaginal and intramuscular progesterone, acetylsalicylic acid, and spasmolytics.

Screening exams and prenatal tests (Duo Test and fetal DNA research in maternal blood) were negative.

At 32 weeks of gestation, the patient stopped therapy with acetylsalicylic acid and started enoxaparina 40,000 U (1 fl s.c./die).

At 37 weeks, the patient went into spontaneous labor, necessitating a cesarean section to have better control of bleeding risk.

No adverse events occurred during delivery. At the time of delivery, the neonatologist was present and confirmed the absence of neonatal pathological changes.

The patient and her child went home on time.

\section{Ethics statement}

This is a case report for which the patient signed the informed consent, providing her approval and consent to publish this report. The authors advise that the approval from Ethics Committee of University Hospital of Salerno was not required.

\section{Discussion}

Uterine AVMs are rare lesions characterized by the presence of shunts between the myometrial arteries and veins., ${ }^{2,510-12}$

Histologically, AVM has very thick venous structure. Arteries have not elastic membrane and muscular tunica media. ${ }^{2,13,14}$
In uterus, these lesions appear as increased vascularization areas within the myometrium (ultrasonography allows this area identification) with a low resistance, high velocity, and turbulent blood flow. ${ }^{10,15}$

The waveform is usually broad with an irregular spectral envelope, suggesting a turbulent flow resulting from the numerous direct arteriovenous connections.

The most frequent presenting symptom of AVM is profuse menorrhagia or metrorrhagia that does not respond to medical treatment, eventually leading to anemia; other symptoms are lower abdominal pain and dyspareunia. In a systematic review, bleeding was reported in $84 \%$ of patients with AVM, and in $30 \%$ of cases of bleeding, blood transfusion was necessary. ${ }^{16-18}$

Barral et $\mathrm{al}^{5}$ described that out of 12 women, three became pregnant after uterine artery UAE, but only one pregnancy was carried to term.

Recently, UAE is used for fibroid therapy. First described in $1995,{ }^{19}$ as a radiological treatment for uncontrolled oncogynecologic and obstetric uterine bleeding, it has become an important conservative therapy for women with symptomatic uterine fibroids. ${ }^{20,21}$

Vilos et al demonstrated that the rate of pregnancy after UAE is lower than after surgical myomectomy, so they recommend embolization only for women that do not desire future pregnancy ${ }^{22,23}$ as a second-line treatment, or in case of contraindication to surgical myomectomy. ${ }^{24}$

Torre et $\mathrm{al}^{23}$ confirmed lower fertility rate, explaining different complications of embolization: the need of hysterectomy after uterus necrosis $(0.2 \%-2 \%),{ }^{25-27}$ persistent amenorrhea $(2 \%-5 \%)^{26-29}$ caused by ovarian insufficiency ${ }^{25,26,30}$ or endometrium atrophy. ${ }^{31}$

The National Institute of Health and Care Excellence guideline from 2010 states that: "patients contemplating pregnancy should be informed that the effects on future fertility are uncertain". ${ }^{32}$ The Royal College of Obstetricians and Gynecologists guideline from 2013 concludes that there is poor evidence regarding fertility after UAE. So UAE treatment in women in fertile age that wish to become pregnant, can take place only after an informed discussion. ${ }^{32}$ The Danish National Guideline confirms those recommendations. ${ }^{32}$ A Cochrane review from 2014 concluded that there were not sufficient evidence to define fertility rate after UAE. ${ }^{32,33}$

Karlsen demonstrated that UAE can result in endometrium ischemia, ${ }^{32}$ and, according to Calzolari, ${ }^{2}$ provokes a "postembolization syndrome", such as massive necrosis and infarction of the uterus, pelvic pain, and uterine artery rupture. ${ }^{34}$ 
In a hysteroscopic and endometrial histologic study carried out 6 months after UAE, it has been revealed that 90\% women had a normal endometrium, but only $37 \%$ revealed entirely normal hysteroscopy findings. ${ }^{35}$

Razavi et al supposed that uterine arteries embolization can induce premature menopause, caused by embolic particles reflux throughout anastomosis formed by uterine and ovarian arteries. ${ }^{36,37}$ Differently, another study showed that $\mathrm{AMH}$ (reliable marker of ovarian reserve) did not decrease after embolization in women of age $<40$ years. ${ }^{1,38}$ Probably, fertility rate reduction is due to another unknown mechanism.

In cases of pregnancy, UAE can cause complications, such as miscarriage, placenta previa or accrete, ${ }^{39,40}$ postpartum hemorrhage, and high cesarean section rate, and intrauterine growth restriction for the fetus. ${ }^{41}$

Contrasting the theories suggesting lower rate of fertility, a review from 2016 concluded that UAE is a procedure as efficient as myomectomy for women that wish to conceive. ${ }^{36}$

In conclusion, our experience from reported clinical case suggests that embolization for uterine AVM executed in symptomatic and hemodynamically unstable patients guarantees both symptoms resolution and the possibility to carry to term a pregnancy, without risks neither for mother nor for fetus.

Yet, surgical therapy remains first choice of treatment for women with uterine fibroids because of lower risks related to this procedure; however, we recommend UAE as first choice of treatment for uterine AVM. Embolization is the only way of allowing women to get pregnant.

\section{Disclosure}

The authors report no conflicts of interest in this work.

\section{References}

1. Kim CW, Shim HS, Jang H, Song YG. The effects of uterine artery embolization on ovarian reserve. Eur J Obstet Gynecol Reprod Biol. 2016;206:172-176.

2. Calzolari S, Cozzolino M, Castellacci E, Dubini V, Farruggia A, Sisti G. Hysteroscopic management of uterine arteriovenous malformation. JSLS. 2017;21(2):e2016.00109.

3. Salazar GM, Petrozza JC, Walker TG. Transcatheter endovascular techniques for management of obstetrical and gynecologic emergencies. Tech Vasc Interv Radiol. 2009;12(2):139-147.

4. Timmerman D, van den Bosch T, Peeraer K, et al. Vascular malformations in the uterus: ultrasonographic diagnosis and conservative management. Eur J Obstet Gynecol Reprod Biol. 2000;92(1):171-178.

5. Barral PA, Saeed-Kilani M, Tradi F, et al. Transcatheter arterial embolization with ethylene vinyl alcohol copolymer (Onyx) for the treatment of hemorrhage due to uterine arteriovenous malformations. Diagn Interv Imaging. 2017;98(5):415-421.

6. Nonaka T, Yahata T, Kashima K, Tanaka K. Resolution of uterine arteriovenous malformation and successful pregnancy after treatment with a gonadotropin-releasing hormone agonist. Obstet Gynecol. 2011; 117(2 Pt 2):452-455.
7. Masciocchi C, Arrigoni F, Ferrari F, et al. Uterine fibroid therapy using interventional radiology mini-invasive treatments: current perspective. Med Oncol. 2017;34(4):52.

8. Kido A, Ascher SM, Kishimoto K, et al. Comparison of uterine peristalsis before and after uterine artery embolization at 3-T MRI. AJR Am J Roentgenol. 2011;196(6):1431-1435.

9. Obele CC, Dunham S, Bennett G, Pagan J, Sung LY, Charles HW. A case of pyomyoma following uterine fibroid embolization and a review of the literature. Case Rep Obstet Gynecol. 2016;2016:9835412.

10. Kelly SM, Belli AM, Campbell S. Arteriovenous malformation of the uterus associated with secondary postpartum hemorrhage. Ultrasound Obstet Gynecol. 2003;21(6):602-605.

11. Diwan RV, Brennan JN, Selim MA, et al. Sonographic diagnosis of arteriovenous malformation of the uterus and pelvis. J Clin Ultrasound. 1983;11(5):295-298.

12. Huang MW, Muradali D, Thurston WA, Burns PN, Wilson SR. Uterine arteriovenous malformations: gray-scale and doppler US features with MR imaging correlation. Radiology. 1998;206(1):115-123.

13. Vijayakumar A, Srinivas A, Chandrashekar BM, Vijayakumar A. Uterine vascular lesions. Rev Obstet Gynecol. 2013;6(2):69-79.

14. Stillo F, Baraldini V, Dalmonte P. Vascular anomalies guidelines by the Italian Society for the study of Vascular Anomalies (SISAV). Int Angiol J Int Union Angiol. 2015;34(2 Suppl 1):1-45.

15. Ginsberg NA, Hammer R, Parihk S, Tamura R, Sabbagha RE. Arteriovenous malformation of the uterus associated with a missed abortion. Ultrasound Obstet Gynecol. 1994;4(3):235-237.

16. Timmerman D, Wauters J, Van Calenbergh S, et al. Color Doppler imaging is a valuable tool for the diagnosis and management of uterine vascular malformations. Ultrasound Obstet Gynecol. 2003;21(6): 570-577.

17. Peitsidis P, Manolakos E, Tsekoura V, Kreienberg R, Schwentner L. Uterine arteriovenous malformations induced after diagnostic curettage: a systematic review. Arch Gynecol Obstet. 2011;284(5):1137-1151.

18. Manolitsas T, Hurley V, Gilford E. Uterine arteriovenous malformationa rare cause of uterine haemorrhage. Aust N Z J Obstet Gynaecol. 1994;34(2):197-199.

19. Ravina JH, Herbreteau D, Ciraru-Vigneron N, et al. Arterial embolisation to treat uterine myomata. Lancet. 1995;346(8976):671-672.

20. Carranza-Mamane B, Havelock J, Hemmings R. Reproductive endocrinology and infertility committee, special contributor. The management of uterine fibroids in women with otherwise unexplained infertility. J Obstet Gynaecol Can. 2015;37(3):277-285.

21. Lefebvre GG, Vilos G, Asch M. Society of Obstetricians and Gynaecologists of Canada, Canadian Association of Radiologists, Canadian Interventional Radiology Association. Uterine fibroid embolization (UFE). J Obstet Gynaecol Can. 2004;26(10):899-911, 913-928.

22. Vilos GA, Allaire C, Laberge P-Y, Leyland N. Special contributors. The management of uterine leiomyomas. J Obstet Gynaecol Can. 2015; 37(2):157-178.

23. Torre A, Fauconnier A, Kahn V, Limot O, Bussierres L, Pelage JP. Fertility after uterine artery embolization for symptomatic multiple fibroids with no other infertility factors. Eur Radiol. 2017;27(7): 2850-2859.

24. Hovsepian DM, Siskin GP, Bonn J, et al. Quality improvement guidelines for uterine artery embolization for symptomatic leiomyomata. J Vasc Interv Radiol. 2009;20(7 Suppl):S193-S199.

25. Spies JB, Spector A, Roth AR, Baker CM, Mauro L, Murphy-Skrynarz K. Complications after uterine artery embolization for leiomyomas. Obstet Gynecol. 2002;100(5 Pt 1):873-880.

26. Walker WJ, Pelage JP. Uterine artery embolisation for symptomatic fibroids: clinical results in 400 women with imaging follow up. BJOG. 2002;109(11):1262-1272.

27. Pron G, Mocarski E, Bennett J, et al. Pregnancy after uterine artery embolization for leiomyomata: the Ontario multicenter trial. Obstet Gynecol. 2005;105(1):67-76. 
28. Spies JB, Ascher SA, Roth AR, Kim J, Levy EB, Gomez-Jorge J. Uterine artery embolization for leiomyomata. Obstet Gynecol. 2001; 98(1):29-34.

29. McLucas B, Adler L, Perrella R. Uterine fibroid embolization: nonsurgical treatment for symptomatic fibroids. J Am Coll Surg. 2001;192(1): 95-105.

30. Chrisman HB, Saker MB, Ryu RK, et al. The impact of uterine fibroid embolization on resumption of menses and ovarian function. $J$ Vasc Interv Radiol. 2000;11(6):699-703.

31. Tropeano G, Litwicka K, Di Stasi C, Romano D, Mancuso S. Permanent amenorrhea associated with endometrial atrophy after uterine artery embolization for symptomatic uterine fibroids. Fertil Steril. 2003; 79(1):132-135.

32. Karlsen K, Hrobjartsson A, Korsholm M, Mogensen O, Humaidan P, Ravn P. Fertility after uterine artery embolization of fibroids: a systematic review. Arch Gynecol Obstet. 2018;297(1):13-25.

33. Gupta JK, Sinha A, Lumsden MA, Hickey M. Uterine artery embolization for symptomatic uterine fibroids. Cochrane Database Syst Rev. 2014;12:CD005073.

34. Wu YC, Liu WM, Yuan CC, Ng HT, Yc W, Ht N. Successful treatment of symptomatic arteriovenous malformation of the uterus using laparoscopic bipolar coagulation of uterine vessels. Fertil Steril. 2001; 76(6):1270-1271.
35. Mara M, Fucikova Z, Kuzel D, Maskova J, Dundr P, Zizka Z. Hysteroscopy after uterine fibroid embolization in women of fertile age. J Obstet Gynaecol Res. 2007;33(3):316-324.

36. Mclucas B, Voorhees WD, Elliott S. Fertility after uterine artery embolization: a review. Minim Invasive Ther Allied Technol. 2016; 25(1):1-7.

37. Razavi MK, Wolanske KA, Hwang GL, Sze DY, Kee ST, Dake MD. Angiographic classification of ovarian artery-to-uterine artery anastomoses: initial observations in uterine fibroid embolization. Radiology. 2002;224(3):707-712.

38. McLucas B, Voorhees WD, Chua KJ. Anti Müllerian hormone levels before and after uterine artery embolization: a preliminary report. Minim Invasive Ther Allied Technol. 2015;24(4):242-245.

39. Soeda S, Kyozuka H, Suzuki S, Yasuda S, Nomura Y, Fujimori K. Uterine artery embolization for uterine arteriovenous malformation is associated with placental abnormalities in the subsequent pregnancy: two cases report. Fukushima J Med Sci. 2014;60(1):86-90.

40. Delotte J, Chevallier P, Benoit B, Castillon JM, Bongain A. Pregnancy after embolization therapy for uterine arteriovenous malformation. Fertil Steril. 2006;85(1):228-228.

41. Grivell RM, Reid KM, Mellor A. Uterine arteriovenous malformations: a review of the current literature. Obstet Gynecol Surv. 2005;60(11): 761-767.
International Journal of Women's Health

\section{Publish your work in this journal}

The International Journal of Women's Health is an international, peerreviewed open-access journal publishing original research, reports, editorials, reviews and commentaries on all aspects of women's healthcare including gynecology, obstetrics, and breast cancer. The manuscript management system is completely online and includes

\section{Dovepress}

a very quick and fair peer-review system, which is all easy to use. Visit http://www.dovepress.com/testimonials.php to read real quotes from published authors. 